John Dewey Society: 2013 Past President's Panel

\title{
Literary Art in the Formation of the Great Community: John Dewey's Theory of Public Ideas in The Public and Its PROBlems
}

\section{Leonard Waks}

\section{INTRODUCTION}

John Dewey presented The Public and Its Problems in a series of lectures in 1926, shortly after Walter Lippmann published two influential works, Public Opinion (1922) and The Phantom Public (1925). In those works, Lippmann had denied that broad publics should share in determining public policy. He argued that the policy issues were far removed from the lives of ordinary citizens, whose collective opinion, as a result, would inevitably be ill-informed, self-interested and readily manipulated.

Dewey countered that the problem of public opinion was not primarily lack of information, but rather of community formation. A democratic community, he argued, could overcome the ignorance and narrow self-interest that plagued its members as isolated individuals. Thus Dewey shifted the question; he asked how a democratic community in the relevant sense could form and intelligently exert its influence upon its governors under modern conditions. In The Public and Its Problems, Dewey sets out to state the necessary conditions of community formation.

His answer focuses on "freedom of social inquiry and of distribution of its conclusions."1 But he acknowledges that free inquiry and free distribution of its results are not enough; they must be accompanied by a corresponding freedom in the "art of presentation." The reading public, he said, rarely attends to serious investigations of social problems. But they can be engaged by presentations drawing on the "potency of art." Social investigation freed from technical jargon and narrow disciplinary specialization would, he argued, have

... such an enormous and widespread human bearing that its bare existence would be an irresistible invitation to a presentation of it which would have a direct popular appeal. The freeing of the artist in literary presentation, in other words, is as much a precondition of the desirable creation of adequate opinion on public matters as is the freeing of social inquiry. ${ }^{4}$ 
Artistic presentation of social investigations could thus transform members of the Great Society into a Great Community, breaking through the crust of habits that isolate members as atomic individuals.

Dewey has nothing more to say in The Public and Its Problems about just how art can weld individuals into a community, thus leaving an important gap in his argument. This topic, however, is addressed throughout Dewey's middle and later works. In this paper, I draw on this body of work to flesh out that crucial phase of argument in PP. The double merger account I offer of Dewey's conception of literary art in the formation of democratic community also illuminates hidden connections between the 'Great Community' (chapter 5) and local face-to-face communities highlighted in 'The Problem of Method' (chapter 6). The paper aims to make the argument of The Public and its Problems clear; it should not be read as endorsing Dewey's theory of art and society in all particulars.

A natural place to start in explicating Dewey's notion of the power of art is Art as Experience. While Dewey wrote that work after The Public and Its Problems, he had already developed many of its key themes in Democracy and Education and Experience and Nature, as well as in several minor works. We can thus draw on works subsequent to The Public and Its Problems to the extent that these later works are continuous with such earlier works.

\section{The Artist And the Work of Art}

In Art as Experience, Dewey shifted attention from finished works of art to processes of making and appreciating art. Dewey's analysis involves a triadic relationship of artist, work, and audience. He conceived artist and audiences as live creatures, engaged in a continuous and cumulative interaction with their worlds, with experience as a natural byproduct. To understand finished art products, he argued, we must start with the materials of everyday experience.

Humans shape these materials in experience as they pursue their aims in every area of life. Sometimes the situation of action is well-organized in experience; it makes sense and actors, relying on settled habits, can sustain action in pursuit of their aims. At other times habitual response is frustrated and action fails, while at still other times the situation is sufficiently confused or indeterminate that energies are entirely blocked and action can't even get going; experience takes on a dull, static quality.

Thought and effort can sometimes bring the materials of experience together in a satisfying way. The situation then attains a sense of organized unity; it makes sense and actors feel emotional release. The experience is consummatory: the actors are not merely experiencing but having an experience. Humans bringing thought and effort, guided by prior experiences and reflections, to bear upon indeterminate situations in any area of life are in this sense engaged in art. There is thus art in science, politics, and friendship, travel, home-making, and 
the process of living itself. In those special fields which we have distinguished as the arts-drawing and painting, literature, dance, and the like-human creators select, refine, and reorganize the materials of everyday experience to create intensified experiences which are deeply engaging and satisfying without immediate reference to other ends.

\section{Particularity, Selection and Abstraction in Art}

In making art, artists in these special fields engage with materials in interactions that have an immediate personal meaning for them. Starting with the art of painting, Renoir, for example, didn't paint just flesh, but this particular flesh—face, arms and breasts-of a particular model that attracted him and evoked an intensified interest. The materials of experience are in this way particular and personal. If the artist attempted merely to reproduce the materials, however, a simple photograph might do, but such snapshots are notoriously lifeless and boring. The artist's receptive capabilities are visceral-organic and unconscious-and far outstrip those of a mechanical device like a camera. Similarly, if the artist merely starts out with a generalized conception of flesh-let us say following a rule of thumb in the representation of skin tone-the image will also be lifeless, striking viewers as merely abstract and conceptual; like artists, viewers also relate to reality viscerallyattending to people, not stick figures.

\section{Selection}

Rather than merely reproducing the materials of experience, visual artists, working within the medium of their art-paint, canvas, color, line, brush strokeselect, refine, and reorganize the particular materials of the initiating experience to make a new, intensified, and emotionally impactful experience in its own right. Dewey states,

It is everywhere accepted that art involves selection. Lack of selection or undirected attention results in unorganized miscellany. The directive source of selection is interest; an conscious but organic bias toward certain aspects and values of the complex and variegated universe in which we live.... An artist is ruthless, when he selects, in following the logic of his interest. ${ }^{5}$

In so doing, an artist extracts from the initiating experience what is personally significant in it for him or her. As Dewey puts this point,

Drawing is drawing out; it is extraction of what the subject matter has to say in particular to the painter in his integrated experience. Because the painting is a unity of interrelated parts, every designation of a particular figure has, moreover, to be drawn into a relation of mutual re-enforcement with all other plastic means-color, light, the spatial planes and the placing of other parts. ${ }^{6}$ 


\section{Abstraction}

This process involves abstraction. As Dewey observes, "Every work of art 'abstracts' in some degree from the particular traits of objects expressed." The artist begins with materials as encountered in experience but abstracts from them, shapes and reshapes them as elements of a new experience that nonetheless retains the particularity and hence the vitality of the original. While a still life, for example, works with everyday materials such as apples and bottles,

a still life by Chardin or Cézanne presents these materials in terms of relations of lines, planes and colors inherently enjoyed in perception. This re-ordering could not occur without some measure of 'abstraction' from physical existence. ${ }^{8}$

Speaking of Renoir's nudes, Dewey states,

The voluptuous qualities of flesh are retained, even_accentuated. But conditions of the physical existence of nude bodies have been abstracted from. Through abstraction ... ordinary associations with bare bodies are transferred into a new realm, for these associations are practical stimuli which disappear in the work of art. ${ }^{9}$

\section{Literary Art}

The same processes of selection and abstraction from particulars are also at work in literary art-in poetry, drama, fiction, and the essay. Literary art is perhaps the "most unmixed and the simplest record of the consummation of human endeavor." ${ }^{10}$ By writers' 'ruthless selection' of material, they can create works that are so unmixed and simple that all extraneous and distracting elements are eliminated, thus prompting immersive, deeply penetrating and moving, experiences for their audiences. This kind of immersion represents the initial merger experience in my account of the role of literary art.

In Dewey's appreciative essay on Tolstoy, a work of unique relevance for grasping his understanding of the social potency of art, Dewey notes that in both Tolstoy's fiction and his social and philosophical essays,

$\mathrm{He}$ (Tolstoy) did not start out from general principles or from purely intellectual difficulties. Some actual and individualized happening, involving the suffering and joy of some actual human being, struck him, impressing him so deeply that it stayed by him, and tortured him. ${ }^{11}$

Tolstoy's entire political philosophy, Dewey offers, grew out of a concrete experience of a public hanging. And when Tolstoy visited the slums,

the eye and emotion of the artist showed him that the problem was concrete, not abstract. He really, not merely conventionally, saw the individual 
human beings: 'the scolding old women, the light-hearted old men, and the sliding boys. ${ }^{\prime 2}$

Literary artists, like their visual counterparts, do not merely reproduce particulars; they reflect upon them, select and reorganize elements and abstract from them. Tolstoy's impressions, Dewey observes, stayed with him and tortured him until he drew more general lessons from them that pointed beyond them, until he "discovered a general reason for a whole class of failures and perplexities."13 Dewey thus concludes his discussion of literary method in the treatment of social issues:

Having first seen the problem in the concrete, in the entanglements of human beings in perplexities that vitally concern them, his method and his conclusion within the sphere of abstract reflection are likely to retain a reality and a force of appeal that do not belong to theories that begin as well as end with generalities. ${ }^{14}$

\section{Art And Value}

Dewey connected appreciation to subsequent action through his analysis of the concept of value. For Dewey, value depends upon placing consummatory enjoyments in the continuous and cumulative lives of live creatures in a continuum of means-ends.

In his Introduction to Volume 2 of the Later Works, James Gouinlock illustrates this idea by asking us to imagine a hiker lost in the woods. The hiker hears lumbermen working nearby and, guided by their sounds, he locates the workers. He likes this turn of events; he is no longer lost. The situation has value, however, not primarily because he likes it but because of what follows in subsequent experience-that he can get home, he can get on with his life and restore its continuity. ${ }^{15}$ The same analysis applies to aesthetic value; the value of appreciative experience of art does not lie primarily in the enjoyment of works of art (though of course such experiences are enjoyable) but in the meanings generated in creative processes and in the subsequent actions enabled by the enjoyment of their products. Literary communication, in particular, is, on the one hand, a contribution to immediate enjoyment of life, while, on the other, a form of action, in that its instrumental use is always a means for concerted action. ${ }^{16}$ This is a paradigm for art in community formation, as we shall see.

\section{Audience ANd COMmunity}

As Dewey stressed in Democracy and Education, works of art enter into the experience of both the artists who create them and their audiences (including other artists). Artists bring something personal to the creation of art works, ${ }^{17}$ and audiences bring personal background experiences to their apprehension of those works. ${ }^{18}$ So we would not expect their experiences to be identical.

But artists and audiences alike share existential conditions of living. Their states of mind and consciousness are objective, in the sense that they are natural 


\section{LEONARD WAKS}

events shaped like other natural events by shared objective conditions. ${ }^{19}$ Unless completed works are mere subjective outpourings of subjective states far removed from everyday life (Dewey, contrary to some Romanticist theorists, would not accept these as works of art), the works prompt similar, though of course not identical, enjoyments and satisfactions in appreciative audiences to those experienced by their creators. Because the works retain traces of the particulars inspiring the artists in creating the works, they are apprehended by their audiences in terms of instincts analogous to those which the audiences bring to similar events in their own experience. Because art, like knowledge, is communication, the artist must, like any communicator, "find a standpoint which includes the experience of others as well as his own. Otherwise his communication cannot be understood." ${ }^{20}$ Artists" immediate goals may not on a conscious level include the communication of ideas or goads to action, and when they do this limits the expressive power of their works. But "no man is eloquent save when someone is moved as he listens." Thus works of art live only in communication as they "operate in the experience of others." ${ }^{21}$

\section{Community Formation}

Literary art, Dewey states, "furnishes the supreme successes in stating of experiences so that they are vitally significant to others."22 "Vitally significant" here means simply "significant in living." Works of literary art are uniquely capable of entering into the stream of experience, of deepening the meanings in situations we encounter and understand in terms of language, and thus profoundly affect subsequent dispositions to action.

Because the conditions of everyday experience are common among associated individuals, states of mind evoked by works of art are also shared in common; they are in essentials the same states of mind, not just individual states somehow occurring in parallel. They are the same in much the way many radios tuned to the same station produce the same program, though of course with variations conditioned by differences in antennae, speaker quality, volume, and so on.

\section{Merger Experiences And Community Cohesion}

For this reason, literary art influences the active dispositions not merely of individuals taken distributively, but also the dispositions of groups-of associated individuals taken collectively. Forms of language, indeed, are "unrivalled in ability to create ... a concerted consensus of action." ${ }^{23}$ And, as Dewey noted in Experience and Nature, no "mode of action is as fulfilling and rewarding" as that concerted consensus, because it "brings with it the sense of sharing and merging in a whole." 24 Dewey is here thinking of examples such as books read and discussed by large fractions of the reading public, or dancers swaying in harmony to a swing band. Dewey was a powerful advocate of the power of the popular arts, and his analysis easily extends to participants at rock concerts and in community mural projects.

\section{E\&C Education and Culture}


All art, Dewey says, "is a process of making the world a different place in which to live, and involves a phase of protest." ${ }^{25}$ Art grows out of the sense that existing conditions at the very least no longer excite and inspire, and involves experimentation and the search for new forms of expression, for salvation from moral arrest, and the discovery of new possibilities. Works of art both contain new worlds of experience and point forward to future social possibilities through concerted action. ${ }^{26}$

Works of art thus create a second sense of merger-a suspension of personal boundaries among their audiences by cutting through entrenched conventions and habits that isolate individuals. But we have to ask, What is unique about art, and literary art in particular, that endows it with the power to ease such a merger in the social body? Why, in other words, is art necessary in the community?

Dewey's answer is that merely intellectual products-the workings of conscious, explicit, cognitive operations of interpretation and calculation-conduce to the sense of individuality; rival arguments and interpretations separate people and place them against each other. Social investigation, however necessary, thus cannot by itself bring people together as a force for change.

In what might be taken as the crux of his argument for the necessity of art in community formation, Dewey asserts that works of art "are the only media of complete and unhindered communication between man and man that can occur in a world full of gulfs and walls that limit community of experience." ${ }^{27}$ In an earlier and more complete statement in a valuable but overlooked essay on "The Moral Significance of the Common School Studies," Dewey said,

One can hardly remind himself too often that works of art are appreciated, not consciously dissected... The appeal is direct and hence unconscious. Somehow, nobody can tell just how, the person responds; he puts himself in tune with the theme and its mode of treatment, he takes on the color of the scene presented. The process is one of silent adjustment, of absorption, of assimilation, involving a gradual making over of personal fibre. Conscious effort to secure the desired moral result may arrest the process of assimilation; it cannot hasten it. Intellectual digestion and reconstruction are slow and organic processes. Conscious short cuts to the end only leave superficial, perverted, and conventional results behind. ${ }^{28}$

\section{From the Work of Art to Local Community}

Literary art as communication is both consummatory and instrumental; it is both an immediate enhancement of life and, in implicitly containing a "claim, appeal, order, direction or request," is also an instrument of collective action. ${ }^{29}$ Despite his general approval of Tolstoy's essays, Dewey rejects Tolstoy's notion that the value of art resides solely in "immediate contagion," its capacity to spread widely shared, emotionally powerful experiences. For Dewey these intensified experiences 


\section{LEONARD WAKS}

are but moments in the continuous and cumulative life histories of these groups. Like the lost hiker who is delighted and relieved to come upon the lumbermen, and thus can see how to get home, the collective audiences of works of art, delighted by their aesthetic experiences, then have to take them on board and get on with their collective lives.

This idea of continuity_ of life after art—connects Dewey's discussion of the Great Community in chapter 5 of The Public and Its Problems with that of local communities in chapter 6 . To see how, let's return to Lippmann. Lippmann saw individuals as biased by narrow self-interest. Dewey countered that individuals are not isolated atoms but form many kinds of associations which reshape their interests and responsibilities and aims - what they are reaching to get. This fact of association leads Dewey to challenge directly Lippmann's thesis that the public's role should be limited to the choice of governors through elections.

Dewey counters this thesis by arguing that the essential value of electoral democracy lies not in the mere selection of leaders, considered in itself, but in the discussions and debates leading up to and following elections. In these communicative activities people reflect on their associated lives and recognize common interests. If these remain unclear, discussions prompt a desire for clarification. Eventually narrow self-interests can be substantially transformed into shared interests. At least the sharper edges of narrow and selfish demands can be filed down. The improvement of conditions for such discussions Dewey thus calls the problem of the public.

Dewey impressively proposed a new kind of public journalism, but he understood that any social investigations uncovering new facts bearing on common interests would be impotent unless through public awareness and discussion they entered fully into the cultural stream and affected the embodied intelligence of all. New insights may at first prevail only within a small minority-even a minority of one. But they can, through broad discussion, eventually become "a possession of the multitude." ${ }^{30}$ In a memorable passage at the close of The Public and Its Problems Dewey then insists that this spread of ideas depends upon intimate face-toface conversations in local communities which rely upon settled relations among participants.

\section{Merger Experiences in Local Conversations as Works of Art}

Dewey's account of intimate conversations in The Public and Its Problems and elsewhere shows how they lift participants from narrow self-interests and forge common action orientations. Significantly, these conversations also depend upon art--for communication is itself an art.

Dewey tells us that "When A and B carry on a conversation together the action is a trans-action: both are concerned in it; its results pass, as it were, across from one to the other." 31 The idea of results passing across is instructive; in conversations participants aim at mutual coordination and become aligned with respect 
to action steps and intended results. This presupposes mutual understanding, but Dewey says that understanding in practice actually means coming to share an action orientation, not just reproducing prior meanings of speakers in the minds of listeners. ${ }^{32}$ As Dewey puts this important point,

The heart of language is not 'expression' of something antecedent, much less expression of antecedent thought. It is communication; the establishment of cooperation in an activity in which there are partners, and in which the activity of each is modified and regulated by partnership. To fail to understand is to fail to come into agreement in action. 33

In aiming at mutual understanding, each conversational partner must be able to assume the roles of the others; that is, each must be able to conceive each other's organization of energies sympathetically, imagining what his or her spoken words in use will mean to each other in the context of that other's organization of future actions to attain his or her ends. As Dewey states in Logic, The Theory of Inquiry, "language ... compels one individual to take the standpoint of other individuals and to see and inquire from a standpoint that is not strictly personal but is common to them as participants or "parties" in a conjoint undertaking." ${ }^{4}$ As he puts this same point earlier in Experience and Nature,

The characteristic thing about $B$ 's understanding of $A$ 's movement and sounds is that he responds to the thing from the standpoint of $A$. He perceives the thing as it may function in $A$ 's experience, instead of just egocentrically. ${ }^{35}$

This response is not primarily intellectual; rather, it is appreciative and depends upon imaginative identification with others. It is only as a result of this intense imaginative mutual awareness that conversation becomes transaction: the results "pass from one partner to the other." ${ }^{36}$ Speakers shape their messages for particular listeners, in concrete situations, with subsequent partnerships for cooperation in view. As a result of this imaginative preparation for and response to the words they speak, they themselves are thus as likely to be altered by their speech acts as are their listeners. ${ }^{37}$

Indeed, they are so closely intertwined in the transaction that it can be difficult even to say where one ends and the other begins. ${ }^{38}$ Their personal boundaries blur and they merge. They reconstruct themselves in the conversation. At least momentarily and provisionally they drop prior, static identities to the point that the statements they make may surprise themselves even more than they surprise others. ${ }^{39}$

Conversational give and take, speaking and listening, are thus acts of imagination that aspire to the status of art. Dewey explains, "Except in dealing with commonplaces and catch phrases, one has to assimilate imaginatively, something of another's experience in order to tell him intelligently of one's own experience. All communication is like art." Like dramatic theatre and the novel, conversation 


\section{LEONARD WaKs}

can both record and sum up the value of what precedes and evoke and prophesy what is to come. ${ }^{40}$ Like art, conversation aims to shape experience as a common possession, ${ }^{41}$ and in isolation and creating experiences combining emotional connection and group consensus it achieves the most satisfying of human pleasures. ${ }^{42}$

\section{CONCLUSION}

Thus, returning to The Public and Its Problems, Dewey holds that the concepts, data and statistical inferences of social investigation are in themselves powerless to affect social change. Only the "potency of art" can break through habits of separation and reconstruct massed individuals into a group sharing a concerted consensus of action-that is, a community. We are now well positioned to explain that thesis.

Our investigation shows that art plays a dual function in community formation through successive merger experiences.

In the first instance, works of art enter into the culture, establishing conditions for engagement and experiential merger in delight. Social investigations bearing on the felt needs and concerns of the public can be presented as journalistic art that, like Tolstoy's essays, begin with concrete and memorable particulars, but through selection, abstraction and re-organization they go beyond the particulars to general lessons about whole classes of cases affected by similar forces and conditions. The initiating social materials are in this way reshaped through literary art until they come together in absorbing, immersive and moving new consummatory experiences.

In the second instance, the conversations stimulated by these journalistic artworks then also function-under conditions prevailing in local communities-as art: as a kind of performance art in which speakers and listeners open to and merge with one another in acts of intensified imaginative appreciation, broadening their initial perspectives and transmuting their private and narrow self-interests into a broad community of interest.

Modern technological media of the Great Community, as Dewey notes, enable the broad distribution of social investigations presented as literary art. Television and the Internet greatly expand the opportunities for this kind of journalism. As these art works are taken up by the public, they stimulate discussion and debate in neighborhood after neighborhood. Through such conversations in town halls, union centers, cafes and saloons and living rooms, the narrow private interests that, for Lippmann, would necessarily distort public opinion can be overcome in practice and a broad community of interest-the Great Community itself-can emerge.

\section{BiBLIOGRAPHY}

Dewey, John. The Collected Works, 1882-1953. Edited by Jo Ann Boydston. 37 vols. Carbondale: Southern Illinois University Press, 1991. 
Lippmann, Walter. Public Opinion. New York: Brace Harcourt, 1922. . The Phantom Public. New York: Brace Harcourt, 1925.

\section{Notes}

1. LW 2:339. All citations of Dewey's works refer to Dewey, John, The Collected Works, 1882-1953, ed. Jo Ann Boydston (Carbondale: Southern Illinois University Press, 1991). EW refers to the Early Works, MW to the Middle Works, and LW to the Later Works; e.g., (LW 2:339) refers to Later Works, Volume 2, page 339).

2. LW 2:339.

3. Ibid., 349.

4. Ibid.

5. LW 10:101.

6. Ibid., 98 .

7. Ibid., 100 .

8. Ibid., 98 .

9. Ibid., 101.

10. MW 4:206.

11. LW 17:381.

12. Ibid., 382.

13. Ibid., 381.

14. Ibid.

15. LW 2:xx.

16. LW 1:144.

17. MW 9:235.

18. MW 4:208.

19. MW 7:45ff.

20. MW 9:235.

21. LW 10:110.

22. MW 9:235.

23. LW 1:145.

24. Ibid.

25. Ibid., 272.

26. Ibid., 273.

27. LW 10:110.

28. MW 4:207.

29. LW 1:144.

30. LW 2:365.

31. Ibid., 244.

32. LW 1:141.

33. LW 12:52.

34. Ibid.

35. LW 1:141.

36. Dewey generalizes this important point from two speakers in conversation to all participants in civilization over time: "In one way everyone is shut off from everyone else. We have, for instance, no access to each other's consciousness, should we choose to be silent; and yet through the medium of my voice you 
somehow or another are enabled to participate in my consciousness; and my consciousness is enabled to expand and enlarge until it gets into the community with yours; so that my consciousness-while it is individual-is also social, because it has taken to itself an indefinite number of thoughts and suggestions coming from everyone in all ages" (LW 17:321).

37. MW 9:8; LW 7:345.

38. MW 9:194.

39. LW 1:152.

40. MW 9:9.

41. Ibid., 12; LW 15:179.

42. LW 1:145.

Leonard Waks is Professor Emeritus of Educational Leadership at Temple University. Email: ljwaks@yahoo.com. 